\title{
PENSAMIENTO POÉTICO Y VARIEDAD MÉTRICA EN LOS PRIMEROS POEMAS DE LEOPOLDO PANERO
}

\author{
POETIC THOUGHT AND METRICAL \\ VARIETY IN THE EARLY POEMS OF \\ LEOPOLDO PANERO
}

\author{
Clara I. Martínez Cantón \\ UNED
}

Resumen: La obra de Leopoldo Panero escrita en su primera etapa poética (aproximadamente entre 1929-1940) presenta gran variedad formal y estilística. Se aprecian claramente dos tendencias distintas: una vanguardista, que métricamente se caracteriza por el uso del verso libre, y otra poesía más intimista, que liga con lo que luego serán sus poemas posteriores y que métricamente se asocia a una versificación regular que utiliza esquemas estróficos tradicionales. El análisis de sus Primeros poemas y sus Versos al Guadarrama puede dar cuenta de estas dos formas de versificar distintas y de la importancia del aspecto métrico para Leopoldo Panero.

Palabras clave: Primeros poemas, Versos al Guadarrama, Leopoldo Panero, poética, vanguardismo, variedad estrófica, variedad métrica.

Abstract: The work of Leopoldo Panero written during his first poetic phase (about 1929-1940) presents a wide range of formal and stylistic variety. It is possible to notice clearly two distinct trends: an avant-garde one, which is metrically characterized by the use of free verse, and a more intimate poetry, closer to his lat- 
er work, which is associated with regular versification and the use of traditional strophic forms. The analysis of his Primeros poemas and Versos al Guadarrama may give an overview for these two different forms of versification and the importance of metrics in this poetic stage of Leopoldo Panero.

Key words: Primeros poemas, Versos al Guadarrama, Leopoldo Panero, poetics, avant-gardism, stanzaic variety, metrical variety. 


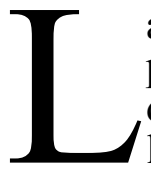

a idea de realizar este trabajo surge primeramente con la publicación en 2007 de las Obras completas de Leopoldo Panero, cuya lectura deja ver la gran variedad y evolución que la métrica del autor va experimentando. Ya más recientemente, la asistencia al segundo Encuentro literario sobre la Escuela de Astorga realizado en enero de 2012 reaviva este proyecto. En este encuentro se habla de la gran variedad formal que caracteriza la poesía de Leopoldo Panero, tanto en sus primeros tanteos ligados al surrealismo como posteriormente, en un tipo de poesía muy distinta, arraigada, como ya se ha hecho usual decir, enraizada a la tierra, la familia y Dios. La lectura de su poesía hace patente claramente este uso de los más diversos metros desde un primer momento. Ya Dámaso Alonso lo destaca: «Panero es un poeta en completa maestría de sus medios expresivos», dejando claro la utilización de los más diversos metros y estrofas por parte del autor ${ }^{1}$. También su hijo Juan Luis hace referencia expresa en su prólogo a las Obras completas a este dominio técnico del verso a la «la variedad y la búsqueda continua y exigente ${ }^{2} \gg$.

Resulta curioso que Panero ligara la parte formal de su poesía, en la que se incluye precisamente el metro, no a una intención específica del poeta sino a una tradición que este recibe:

${ }^{1}$ Alonso, Dámaso: «La poesía arraigada de Leopoldo Panero», en PANERo, Leopoldo: Obra completa, vol. I, edición crítica de Javier Huerta Calvo con la colaboración de Javier Cuesta Guadaño y Juan José Alonso Perandones. Astorga: Ayuntamiento de Astorga, 2007, p. XLVI (Publicado por primera vez en 1949 en Cuadernos Hispanoamericanos, 9, pp. 691-709).

2 Panero, Juan Luis: «Prólogo» a Panero, Leopoldo: Obras completas, Vol. I, Poesías, edición prologada, ordenada y anotada por Juan Luis Panero. Madrid: Editorial Nacional, 1973, p. 15. 
Los otros aspectos, los más formales y exteriores, puede analizarlos y estudiarlos, igual o mejor que el poeta mismo, el crítico profesional, $\mathrm{y}$, en realidad, no pertenecen al poeta, puesto que éste los toma directa o indirectamente de la tradición y del depósito viviente, artístico o popular, del lenguaje ${ }^{3}$.

Veremos, sin embargo, que en su obra todos estos aspectos formales están sumamente cuidados y no son únicamente aspectos técnicos del verso sino que responden a una significación más profunda.

En este trabajo se pretende realizar un análisis y una reflexión sobre los poemas de Leopoldo Panero recogidos bajo el título de Primeros poemas en la magnífica edición crítica de su Obra completa llevada a cabo por Javier Huerta Calvo y publicada en 2007 por el Ayuntamiento de Astorga. Estas composiciones, ya recopiladas en gran parte en la edición de Juan Luis Panero (a falta de 5 composiciones presentes en la de Huerta Calvo), son las primeras publicaciones del joven Leopoldo Panero en diversas revistas, y aparecen entre el año 1928 y 1935. Es importante señalar que en ambas ediciones se ligan estos iniciales tanteos poéticos al surrealismo, y se destaca que la redacción de estos poemas coincide temporalmente con los incluidos en su Versos al Guadarrama, que fueron escritos entre 1930 y 1939. Sin embargo, las dos ediciones observan la gran diferencia estética y de intención artística entre ambos libros, y la de Huerta Calvo califica estos Versos al Guadarrama como «de mayor sinceridad expresiva ${ }^{4} \gg$. Como ya hemos dicho, intentaremos describir y observar las características principales de los moldes métricos utilizados en estos Primeros poemas y compararlos con aquellos escritos en la misma época pero de muy distinto carácter, los de Versos al Guadarrama.

${ }^{3}$ PANERo, Leopoldo: «Unas palabras sobre mi poesía», en PANERo, Leopoldo: En lo oscuro, edición crítica de Javier Huerta Calvo con la colaboración de Javier Cuesta Guadaño y Juan José Alonso Perandones. Astorga: Ayuntamiento de Astorga, 2011, p. 315.

${ }^{4}$ Huerta Calvo, Javier: «Aparato crítico a Obra Completa» en Panero, Leopoldo: Obra completa, vol. II, cit., p. 809. 


\section{Primeros Poemas}

La obra de Leopoldo Panero se suele dividir en tres etapas. La primera abarcaría desde sus primeras publicaciones en 1929 hasta 1940, coincidiendo con el final de la guerra civil. Se suele considerar como una época de aprendizaje y experimentación. La segunda corresponde a los años 40, cuando el poeta, ya en la edad madura, encuentra su propia voz. La última es la que abarca los años 50, en la que publica su Canto personal que tanta polémica causó.

En los años treinta Leopoldo Panero únicamente publica unos pocos poemas diseminados en varias revistas. La causa, como señala Huerta $\mathrm{Calvo}^{6}$, no es el descuido o la falta de diligencia, sino más bien un criterio selectivo muy exigente que mantendrá durante toda su andadura poética, lo que le lleva a dudar sobre la calidad de determinadas composiciones, como le confiesa en una carta a Dionisio Ridruejo:

Cada día creo más sinceramente que sólo la poesía esencial cuenta a la larga y que es enormemente difícil hacer poesía esencial, dar una expresión y una unidad última a nuestra intimidad espiritual. De ahí viene mi lentitud, mi continuo tanteo, mi pudor, si es posible dar ese nombre a la ambición más genuina, al tenaz esfuerzo estético y vital que toda poesía resume en su sustancia ${ }^{7}$.

De esta primera época, como ya advertíamos, se suele destacar su estética vanguardista, ligada, en general, a una métrica versolibrista. Huerta Calvo describe esta etapa de la siguiente manera:

Época de aprendizaje y de descubrimientos: en lo político adhesión entusiasta a la Segunda República y querencias hacia la izquierda; en lo poético, militancia vanguardista, más formal que verdaderamente sentida pues revela lo novedoso y mantiene en secreto lo auténtico. En otras palabras: la razón acata el dictado de los nuevos lenguajes -creacionista, surrealista-, pero el corazón se siente más cercano a la expresión humanística de quien a partir de entonces será su modelo en casi todo, don Antonio Machado 8 .

\footnotetext{
${ }^{5}$ Seguimos en este punto a Huerta Calvo en Huerta CALvo, Javier: «Introducción a En lo oscuro», en PANERo Leopoldo: En lo oscuro, cit., pp. 28-29.

${ }^{6}$ Ibid., p. 18.

${ }^{7}$ Ibid.

${ }^{8}$ Ibid., p. 28.
} 
La visión que Panero mismo da posteriormente, en 1965, de la poesía de aquella época de juventud es la de una situación en la que la poesía había llegado a una experimentación tal que en cierto modo ahogaba el sentimiento y la expresión verdadera. Habla de una situación «desesperada», ya que el creacionismo y el surrealismo habían llegado al «non plus ultra o callejón sin salida a que históricamente había abocado la poesía española y la poesía del mundo entero ${ }^{9} »$. Ante esta situación el joven poeta astorgano parece no saber qué camino tomar y escribe simultáneamente versos de corte vanguardista, en los que experimenta con el lenguaje y las formas; y versos con un tono distinto, más similares a lo que sería su poesía posterior y que indudablemente remiten a la poesía de Antonio Machado.

El propio Panero contrapone los dos tipos de poesía que representan Primeros poemas y Versos al Guadarrama en una conferencia publicada en 1965 :

La poesía que, dentro de mi obra, corresponde espiritual y cronológicamente a aquel momento de retorno a lo humano, de vuelta al sentimiento, de regreso a los temas líricos tradicionales y eternos: el amor, la muerte, la tierra y el paisaje de España, está vinculada elegíacamente a los pinares y canchales de la sierra del Guadarrama, a la luz de sus cumbres y al aroma de sus retamas y piornos, a través de una juvenil experiencia amorosa idealizada por el recuerdo y el dolor. Estos versos que publiqué en colección años más tarde, titulándolos simplemente Versos al Guadarrama, datan en su redacción primitiva de 1930 a 1932, y permanecieron durante mucho tiempo inéditos entre mis papeles, como sin atreverse a salir a la luz pública, y sólo tímidamente leídos y comunicados por mí a los amigos más cercanos, con cierto aire de clandestinidad. Mientras esto hacía, publicaba, en cambio, en una y otra revista de avanzada poética bastantes poemas creacionistas y surrealistas, pero sobre todo verbalistas, siguiendo el último grito de las más recientes antologías puras ${ }^{10}$.

Como luego se hará patente en el análisis métrico, Panero relaciona el retorno a «los temas humanos y directos» con el uso de formas tradicionales.

Su primer poema publicado data de 1929 en Nueva revista.

${ }^{9}$ Ibid., p. 316.

${ }^{10}$ Ibid., p. 317. 
Notación literaria, en la que publica 3 poemas creacionistas. Sus poetas predilectos de la época eran Huidobro y Gerardo Diego. Otros poetas del 27, como Guillén o Alberti, también eran muy leídos por el joven Panero, lo que se refleja en el homenaje que hace a Góngora (OC Poesía, 7), en un poema con forma de romance heroico y lenguaje sumamente cuidado. Huerta destaca que en esos años «de entre todas las tendencias el joven Panero parece decantarse por un surrealismo a la española [...] de un versolibrismo generoso ${ }^{11} \gg$.

Sin embargo, ya en estos primeros poemas se advierte el cuidado de Leopoldo Panero por la forma, lo que se hace patente en que no se queda en un único modo de versificar, sino que va probando distintos moldes. La forma más clara de verlo es quizás mediante una tabla que recoja los datos métricos principales de estas composiciones que forman sus Primeros Poemas:

\begin{tabular}{|l|c|l|c|c|l|l|}
\hline \multicolumn{1}{|c|}{$\begin{array}{c}\text { Título del } \\
\text { poema }\end{array}$} & $\begin{array}{c}\text { Núme- } \\
\text { ro de } \\
\text { versos }\end{array}$ & $\begin{array}{c}\text { Verso } \\
\text { regular }\end{array}$ & $\begin{array}{c}\text { Esquema } \\
\text { rítmico }\end{array}$ & $\begin{array}{c}\text { Esquema } \\
\text { rimático }\end{array}$ & $\begin{array}{c}\text { Tipo de } \\
\text { rima }\end{array}$ & \multicolumn{1}{|c|}{ Estrofa } \\
\hline $\begin{array}{l}\text { Romance del } \\
\text { nadador y el sol }\end{array}$ & 44 & Regular & 8 & - -a & Asonante & Romance \\
\hline $\begin{array}{l}\text { Crónica, cuando } \\
\text { amanece }\end{array}$ & 30 & Regular & 11 & - A & Asonante & $\begin{array}{l}\text { Romance he- } \\
\text { roico }\end{array}$ \\
\hline $\begin{array}{l}\text { Poema de la } \\
\text { niebla }\end{array}$ & 38 & Regular & 11 & - A & Asonante & $\begin{array}{l}\text { Romance he- } \\
\text { roico }\end{array}$ \\
\hline Agua viva & 14 & Regular & 14 & $\begin{array}{c}\text { ABBA } \\
\text { ABA CDE }\end{array}$ & $\begin{array}{l}\text { Consonan- } \\
\text { te }\end{array}$ & Soneto \\
\hline $\begin{array}{l}\text { Romance y tra- } \\
\text { gedia }\end{array}$ & 54 & Regular & 8 & - -a & Asonante & Romance \\
\hline Mirada & 12 & Libre & - & - & Sin rima & - \\
\hline $\begin{array}{l}\text { Esos hombres } \\
\text { que mueven su } \\
\text { cabeza de tierra }\end{array}$ & 25 & Libre & - & - & Sin rima & - \\
\hline $\begin{array}{l}\text { Oh sacudida de- } \\
\text { sértica de ojos } \\
\text { transparentes }\end{array}$ & 15 & Libre & - & - & Sin rima & - \\
\hline Conferencia & 52 & Regular & 8 & - & Asonante & Romance \\
\hline $\begin{array}{l}\text { Ojos última- } \\
\text { mente sufridos }\end{array}$ & 55 & Libre & - & Sin rima & - \\
\hline
\end{tabular}

${ }^{11}$ Ibid., p. 32. 


\begin{tabular}{|l|l|l|l|l|l|l|}
\hline Nuca de río & 20 & Regular & 14 & ABAB & $\begin{array}{l}\text { Consonan- } \\
\text { te }\end{array}$ & Serventesios \\
\hline $\begin{array}{l}\text { Estoy de paso } \\
\text { en esa escultura } \\
\text { en la noche }\end{array}$ & 46 & Libre & - & - & Sin rima & - \\
\hline $\begin{array}{l}\text { Dame si necesi- } \\
\text { to la respuesta } \\
\text { del mar }\end{array}$ & 31 & Libre & - & - & Sin rima & - \\
\hline $\begin{array}{l}\text { Esa pequeña } \\
\text { hoja retiembla } \\
\text { como una frente } \\
\text { caída }\end{array}$ & 18 & Libre & - & - & Sin rima & - \\
\hline Ejemplo & 14 & Regular & 7 & - & Sin rima & - \\
\hline Honda paloma & 24 & Libre & - & - & Sin rima & - \\
\hline Palabra viva & 22 & Libre & - & - & Sin rima & - \\
\hline $\begin{array}{l}\text { Por el centro del } \\
\text { día }\end{array}$ & 68 & Libre & - & - & Sin rima & - \\
\hline $\begin{array}{l}\text { Conocimiento } \\
\text { del deseo }\end{array}$ & 35 & Libre & - & - & Sin rima & - \\
\hline
\end{tabular}

Estos poemas publicados en revistas durante su juventud son 19 composiciones de entre las cuales encontramos 8 escritas en versificación regular y 11 en verso libre. Los poemas regulares están rimados y se ajustan a una estructura estrófica o composicional conocida (sonetos, romances, serventesios), a excepción de uno de ellos, «Ejemplo», compuesto en heptasílabos blancos, y de «aire guilleninano ${ }^{12}$ ». Parece que la forma por la que el poeta se inclina más en sus poemas regulares es el romance, ya en endecasílabos, ya en octosílabos. Quizás ello se deba a la libertad que dentro de la regularidad otorga, con su rima asonante y su extensión variable.

Los poemas están ordenados según la fecha de publicación, por lo que resulta también muy significativo que los cinco primeros sí se ciñan a un esquema regular, y que luego la mayoría de las composiciones sean ya versolibristas.

El hecho de que estén escritos en versificación regular no siempre indica, no obstante, que no estén ligados al creacionismo o surrealismo. Un caso claro es el poema que abre el libro: «Romance del nadador y el sol», o el «Poema de la niebla», ${ }^{12}$ Gullón, Ricardo: La juventud de Leopoldo Panero. León: Diputación de León, 1985, p. 78. 
en los que se conjugan la temática y los términos vanguardistas con un metro más tradicional. De corte futurista es el poema «Conferencia», escrito como romance octosilábico, y dedicado al teléfono, que utiliza imágenes como «pájaros eléctricos»o «estación auditiva». Sobre su poema dedicado a Gonzalo Goy y escrito en serventesios «Nuca de río», también de carácter vanguardista, rememora Gullón:

Gonzalo, hombre agudo y fino, desafecto a las novedades líricas de la Vanguardia, quedaba ya un poco al margen de la literatura que estaba haciéndose. Al dedicarle sus versos Leopoldo le incorporaba otra vez a la poesía y no sé si intentaba negar o confirmar la idea de que en las vanguardias había algo de afectación y capricho. Para intrigarle escribió el poema, utilizando los recursos y desplegando las modalidades metafóricas que el amigo rechazaba. Fue ésta una de las composiciones de lo que pudiéramos llamar la primera manera de Leopoldo Panero ${ }^{13}$.

No obstante, y a pesar de que siempre se ha destacado el carácter ligado a los experimentos vanguardistas de los primeros poemas publicados por Panero, hay algunos que se salen de esta generalización. Ya comentábamos antes el caso de «Crónica, cuando amanece», de marcada influencia gongorina, escrito en forma de romance heroico. Sin embargo, el poema que quizás llame más la atención por su carácter distinto a los demás sea el único soneto de esta serie: «Agua viva». Huerta Calvo afirma que es en este poema donde «entre tantos ecos se oía ya la voz más auténtica del poeta ${ }^{14} \gg$. Recoge además el testimonio de Juan Guerrero Ruiz, muy revelador de lo que Juan Ramón Jiménez opinaba respecto a este poema: «Me dice que La Libertad de hoy publica un soneto firmado por Leopoldo Panero, que está escrito en el tono de sus Sonetos espirituales, sin modernismos del momento, bastante bien $[\ldots]^{15} \gg$. Es muy significativa la forma métrica escogida, un soneto perfectamente canónico, que parece tener el poder de la concisión, de la expresión comedida.

\footnotetext{
${ }^{13}$ Ibid., p. 67.

${ }^{14}$ Huerta Calvo, Javier: «Introducción a En lo oscuro», cit., p. 33.

${ }^{15}$ Apud Huerta Calvo, Javier: «Aparato crítico a Obra completa», cit., p. 809.
} 
Otra composición que se aleja de las vanguardias del momento, y en la que podemos escuchar ecos lorquianos es «Romance y tragedia», dedicado a dos capitanes, Galán y García Hernández, que se sublevaron en Jaca por la causa republicana, fusilados en 1930.

Gullón, en su libro en el que rememora la juventud de Leopoldo Panero, destaca dos tipos de influencias clave que también la crítica ha recogido. Por una parte, la de los poetas del 27, y entre ellos sobre todo Guillén - «fervoroso entusiasmo guilleniano», dice Gullón ${ }^{16}$-, pero también Alberti, Lorca y Gerardo Diego, que conforman las lecturas claves para esta «primera manera» de su obra de la que Ricardo Gullón habla. Por otra parte y ya posteriormente (1934-1935), la influencia de Luis Rosales, y Juan Ramón Jiménez, y, por supuesto de Antonio Machado, «signo de que iba encontrándose a sí mismo ${ }^{17}$ ».

Pasemos ahora a comentar sus poemas en verso libre. En el siguiente gráfico reflejo la frecuencia de versos de cada número de sílabas:

${ }^{16}$ Gullón, Ricardo: La juventud de Leopoldo Panero, cit., p. 69.

${ }^{17} \mathrm{Ibid}$. 


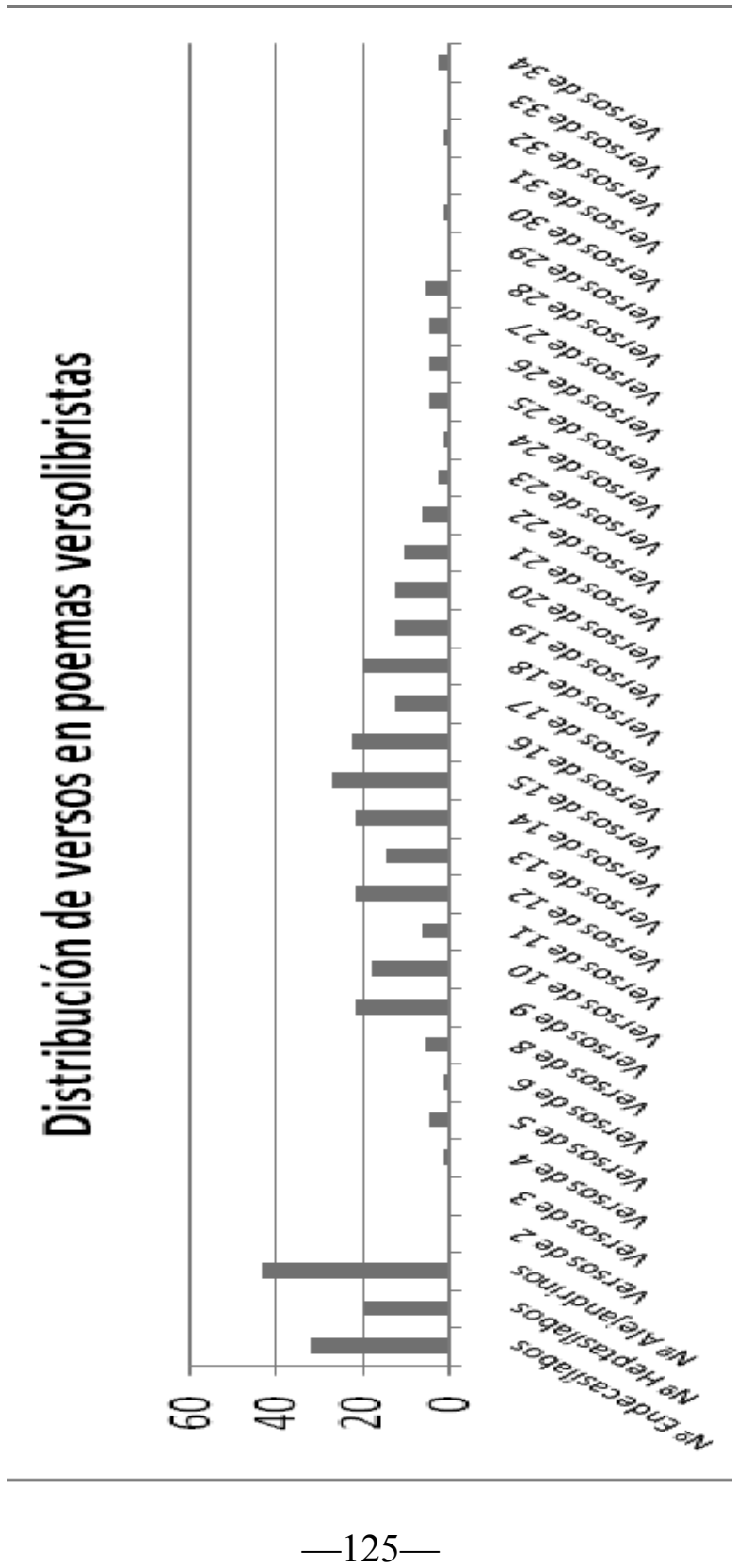


El verso más utilizado en estos poemas versolibristas es el alejandrino. Sin embargo, es fácilmente visible que no hay una medida claramente privilegiada, sino que la mayoría de los versos oscilan entre las nueve y dieciocho sílabas.

Hemos señalado como versos de 11 aquellos que a pesar de tener las citadas sílabas no están acentuados en las que se consideran canónicas para los endecasílabos (los llamados $a$ maiori, 6-10; a minori, 4-8-10; o dactílico, 4-7-10), es decir, serían endecasílabos no tradicionales. Asimismo hemos señalado como versos de 14 sílabas aquellos que son indivisibles según la tradicional fórmula de dos hemistiquios de siete sílabas cada uno. Como vemos, tanto el endecasílabo no tradicional como el verso de catorce sílabas no alejandrino son bastante frecuentes.

En todo caso, se observa claramente que los metros tradicionales de sílabas impares, como alejandrino, endecasílabo y heptasílabo son más frecuentes que otros metros, tendiendo así a un tipo de «verso libre atenuado» ${ }^{18} \mathrm{o}$ "verso libre de base tradicional $\gg{ }^{19}$ muy utilizado en castellano y descendiente de la silva impar, que tanto utilizó Juan Ramón Jiménez y que se centra principalmente en el endecasílabo y sus combinaciones. En Leopoldo Panero encontramos un versolibrismo que combina muy diferentes medidas, pero entre las que predominan las de ritmo endecasilábico. Utiliza, por tanto, un verso libre al estilo de algunos poetas del 27, como Aleixandre, cuyo versolibrismo ha sido ampliamente estudiado por Bousoño llegando a la conclusión de que la gran mayoría de sus versos responden a un ritmo endecasilábico, bien sea por la tendencia hacia metros combinables con el endecasílabo y ya utilizados desde el modernismo o por otros mecanismos, como la combinación de varios metros de este tipo en un solo verso ${ }^{20}$.

Significativo al respecto es el hecho de que Gullón califica los poemas de Panero «Honda paloma» y «Palabra viva», precisamente, como composiciones «entre cuyas líneas, de reso-

${ }^{18}$ Utrera Torremocha, María Victoria: Historia y teoría del verso libre. Sevilla: Padilla Libros, 2001, pp. 297-298.

${ }^{19}$ PARAíso, Isabel: El verso libre hispánico: orígenes y corrientes. Madrid: Gredos, 1985, p. 395.

${ }^{20}$ Bousoño, Carlos: La poesía de Vicente Aleixandre. Madrid: Gredos, 1977, pp. 322323. 
nancia aleixandrina, se traslucen rasgos y acentos claramente personales $^{21} \gg$.

Quizás el ejemplo más extremo de este tipo de métrica que combina versos endecasílabos y combinables con él, con otros compuestos de ritmo endecasilábico sea el poema «Por el centro del día», uno de los últimos que publica en esta etapa. Este poema está marcado por un acontecimiento decisivo para su poética: la llegada a España de Pablo Neruda. «Por el centro del día» fue publicado en Caballo verde para la poesía, y para Rosales es un «poema de despegue con el que finaliza su etapa de experimentación poética vanguardista ${ }^{22} \gg$. Es un poema que también su hijo Juan Luis Panero destacará en su prólogo a las Obras Completas por su mundo onírico y su verso amplio ${ }^{23}$. La distribución de versos la vemos en el siguiente gráfico:

${ }^{21}$ Gullón, Ricardo: La juventud de Leopoldo Panero, cit., p. 78.

22 Rosales, Luis: «Leopoldo Panero hacia un nuevo humanismo». Cuadernos Hispanoamericanos, 1965, 187-188, p. 65.

${ }^{23}$ PANero, Juan Luis: «Prólogo», cit., p. 15. 


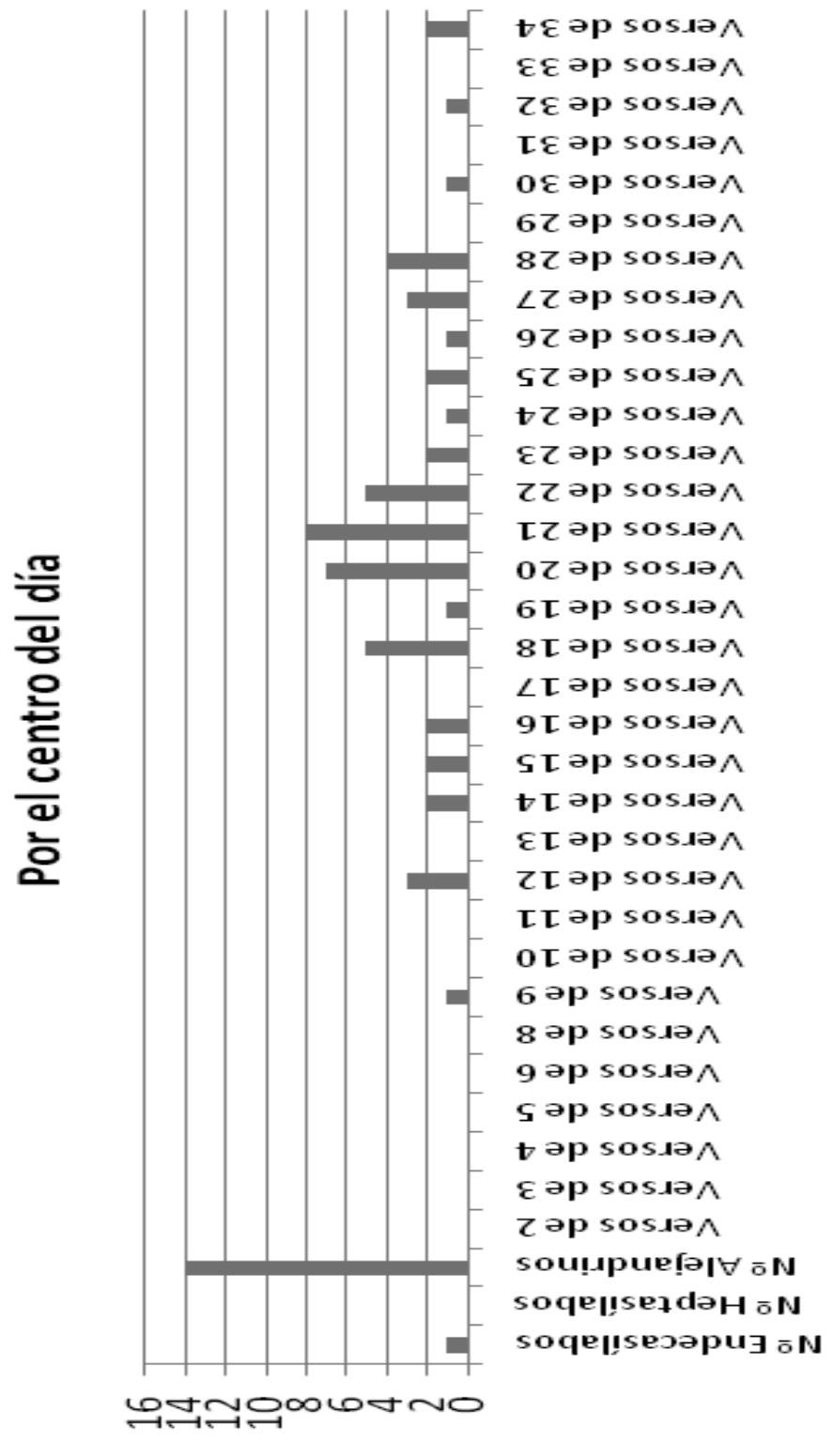


De nuevo hay una gran cantidad de alejandrinos, pero la mayor parte de los versos son mucho más largos, entre dieciocho y veintidós sílabas, $y$, sorprendentemente, encontramos también una cantidad considerable de versos que rondan las treinta sílabas. En el análisis pormenorizado de este poema descubrimos que muchos de estos versos largos son lo que Miguel Ángel Márquez ha denominado versículos y que define como ese «verso compuesto incluido en el verso libre de ritmo endecasilábico, que es la mayor innovación del sistema poético ${ }^{24} »$, cuyos componentes, «sean dos o más "hemistiquios" en un sentido lato permitido por el DRAE, presentan también el ritmo endecasilábico general, es decir, tienen número impar de sílabas $(5,7,9$ y 11 sílabas) ${ }^{25} \gg$. Veamos algunos ejemplos:

En la risa que abre mi corazón de verdes margaritas

La tierra verde canta perfumada de tránsito suave

Sólo queda el misterio, la carne de la sed, la encarnación

[del llanto $[7+7+7+7]$

Cesa el ruido del llanto y su cifra de ángel corre sobre

Si tu mano se abre las margaritas flotan sobre el campo

[las playas $[7+7+7]$

[ligero

$$
\begin{aligned}
& {[7+11]} \\
& {[7+11 \text { o } 11+7]} \\
& {[7+7+7+7]} \\
& {[7+7+7]}
\end{aligned}
$$$$
[7+7+7]
$$

Incluso el verso más largo del poema puede analizarse de esta manera:

Si tu pecho increíble suspira y se acongoja parece que es la muerte

[como un cáliz de espuma y de jilgueros verdes $[7+7+7+7+7]$

Sin embargo, otros versos que sobrepasan las treinta sílabas en esta composición no son fácilmente reducibles a versos simples de ritmo endecasilábico, por lo que no se debe pensar que en Panero encontramos únicamente metros endecasilábicos escondidos dentro de otros mayores:

\footnotetext{
${ }^{24}$ MÁrquez, Miguel Ángel: «El versículo en el verso libre de ritmo endecasilábico». Bulletin of Hispanic studies, 2000, 77, p. 218.

${ }^{25}$ Márquez, Miguel Ángel: «Juan Ramón Jiménez: Etapa americana». Rhythmica. Revista española de métrica comparada, 2003, I, p. 155.
} 
El mar vuelve sobre la playa

y arrebata la arena trémula y las conchas donde han dormido las primeras [violetas de Marzo.

Parece que el amor huye siempre más lejos y su presencia luminosa parece [como la sombra de un deseo.

La versificación libre, entonces, se acerca a la de otros poetas de la época que también experimentaban con las vanguardias. Sin embargo, este tipo de versificación libre que parece reservar el autor para sus poemas surrealistas y creacionistas, aparece también en otros que se acercan más a una poesía más íntima, como puede ser «Mirada», que tanto por su temática amorosa como por su expresión está más lejano del vanguardismo. Reproducimos aquí sus últimos versos:
¿Para quién aquella sonrisa donde se estaba rizando tu alma?
Era una fragancia equivocada.
¡Mis ojos hacia su fin vacío!

Señala Huerta Calvo que para la estudiosa Eileen Connolly «el poema que cristaliza el nuevo modo humanizado de Panero es el que publica en 1934, en la revista Noroeste, y que empieza con el verso "Esa pequeña hoja retiembla como una frente caída" ${ }^{26} \gg$. Huerta Calvo señala que, si bien hay trasuntos de una nueva sensibilidad en esta composición, todavía hay más ligazón con los poemas de vanguardia que con su forma de versificar posterior: «el verbalismo es aún excesivo, casi torrencial, tal lo denuncia el último símil del poema: "Vosotros que vivís como desbocados cascos de caballos o polvorientos insultos / Bebed un poco de agua en la cuenca de la mano y os taladrará el frío amanecer" ${ }^{27} \gg$. Desde mi punto de vista dicho poema, además de tener todavía muchos adjetivos e imágenes de sesgo vanguardista, tiene también una métrica muy ligada a los poemas surrealistas del autor. La mayoría de sus 18 versos tiene entre 13 y 19 sílabas, acusándose así una tendencia hacia el verso largo:

\footnotetext{
${ }^{26}$ Huerta Calvo, Javier: «Introducción a En lo oscuro», cit., pp. 38-39.

${ }^{27}$ Ibid.
} 


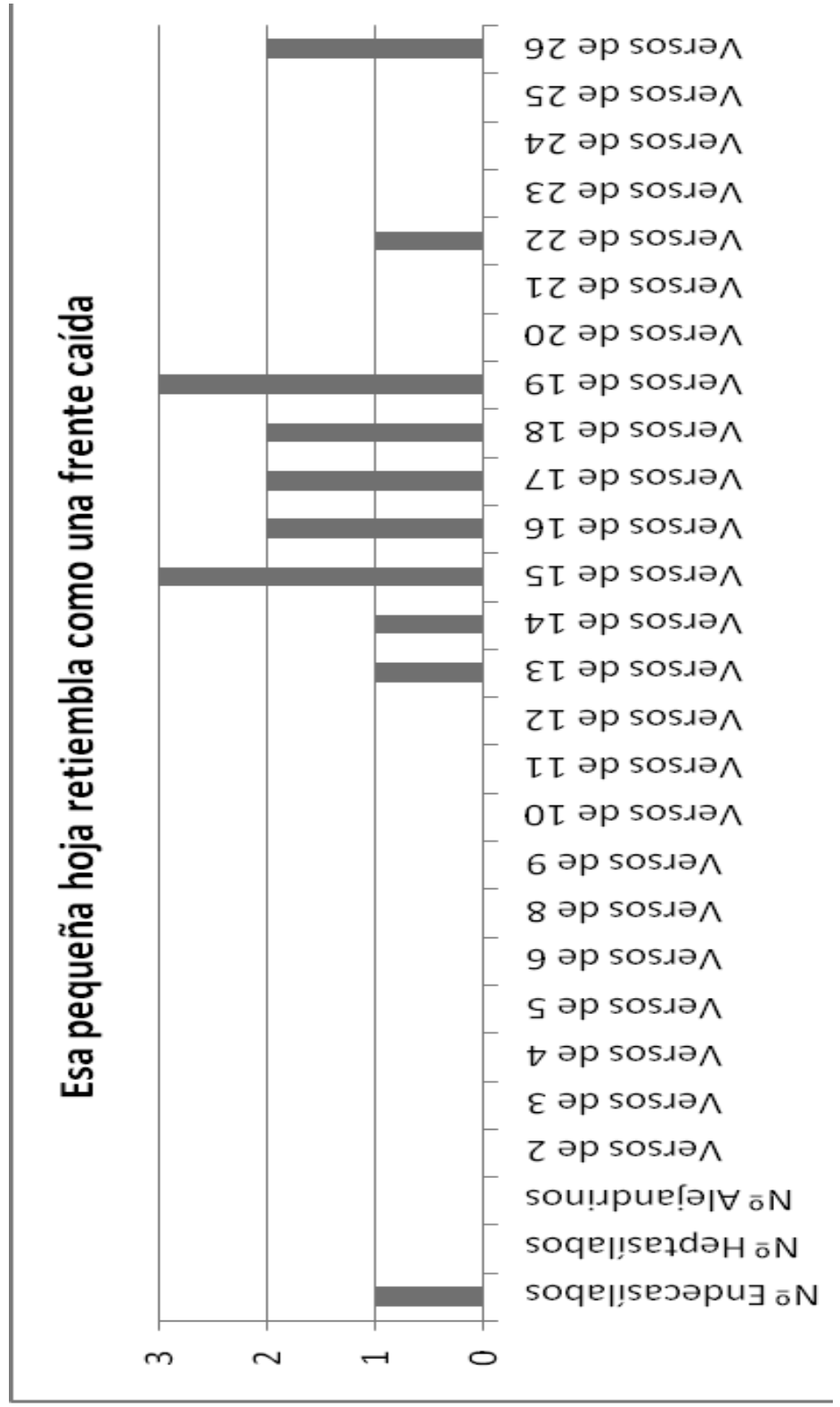


En todo caso, lo que vemos claramente es que el poeta avanza e introduce en este poema motivos más emocionales, como la referencia a la madre, mezclados con otros más típicamente vanguardistas, como la imagen de los versos siguientes: «Campos con su mágica calma donde un potro salvaje / Bellísimo con la mirada desértica acaricia océanos y nubes».

Las vanguardias son para Panero no solo una moda, sino también una fuente de experimentación fértil. Le permiten probar nuevas sonoridades, temas, y metáforas. Huerta Calvo afirma que, para el joven Panero las vanguardias serían «suministradoras inagotables de necesarios experimentos de "audacias técnicas", de "rápidos deslumbramientos expresivos", de "acrobacias verbales"28》. Sin embargo, también se agotan y fuerzan la expresión. Aún así Leopoldo Panero siempre reconocerá su importante valor histórico y creativo:

A pesar de todo el poeta mantendrá siempre una gran admiración por la enorme vitalidad que aquella aventura trajo a la poesía contemporánea: su «múltiple sorpresa creadora», su «histórica amenidad», su «desbordante lección de libertad»; palabras que Panero, no sin nostalgia, escribe en 1954, ya dentro de un contexto poético de signo mayoritariamente «realista», dominado por la monotonía formal y la rutina temática ${ }^{29}$.

Panero habla de que en aquella época la poesía española era «más varia, menos aburrida, más aventurera y arraigada ${ }^{30} »$. Es importante señalar, precisamente, la gran variedad formal que encontramos en estos Primeros poemas de Leopoldo Panero, puesto que serán de alguna manera la base para la gran variedad métrica y formal que caracterizará su obra. En general, después de este análisis de la versificación, los motivos e influencias en estas primeras composiciones del autor, podemos observar que, efectivamente, asistimos a una etapa de búsqueda, de intensas lecturas, de experimentos e innovaciones. Se conjugan así distintos tipos de métrica -regular y libre-, y distintos tipos de poesía e influencias-según hemos visto vanguardista, de resonancias gongorinas, de tipo más lorquiano, de estilo más juanramoniano. Las palabras de Dámaso Alonso sobre el

$\overline{{ }^{28} \mathrm{Ibid}}$., p. 33.

${ }^{29}$ Ibid., p. 34.

${ }^{30}$ PAnero, Leopoldo: «Poesía de ayer», en Obra completa [Prosa], cit., p. 43. 
poeta astorgano reflejan muy bien la riqueza de esta variedad:

Quiere decir esto que Panero es uno de esos escritores que conoce y ha vivido los atrevimientos, los experimentos sobre la expresión que caracterizan a la literatura de entre ambas guerras. Un poeta de hoy, que no renuncia a ninguna de esas altas cotas, ya conseguidas; que usa todos los elementos formales, todos los moldes, ya tradicionales, ya modernos. Lo que a él le interesa es llenarlos, rebosarlos de concentrada emoción y pensamiento ${ }^{31}$.

En general se respeta el tipo de versificación que suele llevar cada estilo poético, pero encontramos también poemas vanguardistas en verso regular, y poemas que tienden hacia una mayor sinceridad expresiva en verso libre. Es importante señalar esto, ya que posteriormente el poeta combinará muy variados tipos de versificación dentro de lo que ya podemos considerar su voz verdadera. Sin embargo, en esta primera época encontramos una separación tajante entre este tipo de poesía de experimentación y la que va escribiendo al mismo tiempo pero que recopilará en sus Versos al Guadarrama y que ahora analizaremos.

\section{Versos al Guadarrama}

Las composiciones de este poemario son publicadas por primera vez en Fantasía (Semanario de la invención literaria), en el número 21, en 1945. No obstante, fueron escritos, como hemos dicho ya en varias ocasiones, en los mismos años que los que componen sus Primeros Poemas. Para Huerta Calvo estos poemas son sin duda mejores y más acordes con su verdadera voz:

Y es que, más allá de estos devaneos vanguardistas, lógicos en alguien procedente de la provincia, ansioso por absorber todas las nuevas de la Modernidad, el joven Panero iba mostrando la verdadera cara de su escritura, los principios que habrían de sustentar su pensamiento literario, de acuerdo con los dictados de Juan de Mairena: sencillez y naturalidad ${ }^{32}$.

Uno de los principales cambios respecto a los poemas publicados anteriormente es, sin duda la métrica. Veámosla en el siguiente cuadro:

${ }_{31}$ Alonso, Dámaso: «La poesía arraigada de Leopoldo Panero», cit., p. XLVI.

${ }^{32}$ Huerta CAlvo, Javier: «Introducción a En lo oscuro», cit., p. 34. 


\begin{tabular}{|c|c|c|c|c|c|c|}
\hline $\begin{array}{l}\text { Título del } \\
\text { poema }\end{array}$ & $\begin{array}{l}\text { N. }{ }^{\circ} \text { de } \\
\text { versos }\end{array}$ & $\begin{array}{l}\text { Versifi- } \\
\text { cación }\end{array}$ & $\begin{array}{l}\text { Esquema } \\
\text { rítmico }\end{array}$ & $\begin{array}{l}\text { Esquema } \\
\text { rimático }\end{array}$ & $\begin{array}{c}\text { Tipo de } \\
\text { rima }\end{array}$ & Estrofa \\
\hline Cumbre, I & 20 & Regular & Endecasílabos & $\begin{array}{c}-\mathrm{A}-\mathrm{A} ;-\mathrm{B}-\mathrm{B} \\
\ldots\end{array}$ & Asonante & Coplas \\
\hline Cumbre, II & 20 & Regular & Heptasílabos & $\begin{array}{c}\text {-a-a; -b-b; } \\
\text { etc. }\end{array}$ & Asonante & Coplas \\
\hline $\begin{array}{l}\text { Pino a pino, } \\
\text { los ojos } \\
\text { (despedida) }\end{array}$ & 14 & Regular & Endecasílabos & $\begin{array}{l}\text { ABBA ABBA } \\
\text { CDE CDE }\end{array}$ & Consonante & Soneto \\
\hline Por la tarde & 14 & Regular & Endecasílabos & $\begin{array}{l}\text { ABBA ABBA } \\
\text { CDE CDE }\end{array}$ & Consonante & Soneto \\
\hline Juntos & 40 & Regular & $\begin{array}{l}\text { Endecasílabos y } \\
\text { heptasílabos }\end{array}$ & $-A$ & Asonante & $\begin{array}{l}\text { Silva arro- } \\
\text { manzada }\end{array}$ \\
\hline $\begin{array}{l}\text { Todo en } \\
\text { vuelo }\end{array}$ & 14 & Regular & Endecasílabos & $\begin{array}{l}\text { ABBA ABBA } \\
\text { CDE CDE }\end{array}$ & Consonante & Soneto \\
\hline $\begin{array}{l}\text { Levantada en } \\
\text { la brisa }\end{array}$ & 28 & Regular & $\begin{array}{l}\text { Endecasílabos y } \\
\text { heptasílabos }\end{array}$ & $-\mathrm{A}$ & Asonante & $\begin{array}{l}\text { Silva arro- } \\
\text { manzada }\end{array}$ \\
\hline $\begin{array}{l}\text { Tras la } \\
\text { sombra de } \\
\text { un día }\end{array}$ & 14 & Regular & Endecasílabos & $\begin{array}{l}\text { ABBA ABBA } \\
\text { CDE CDE }\end{array}$ & Consonante & Soneto \\
\hline $\begin{array}{l}\text { Por donde } \\
\text { van las } \\
\text { águilas }\end{array}$ & 14 & Regular & Alejandrinos & $\begin{array}{c}\text { ABAB } \\
\text { ABAB CDC } \\
\text { DCD }\end{array}$ & Consonante & $\begin{array}{l}\text { Soneto } \\
\text { alejandri- } \\
\text { no }\end{array}$ \\
\hline $\begin{array}{l}\text { Materia } \\
\text { transparente }\end{array}$ & 14 & Regular & Alejandrinos & $\begin{array}{c}\text { ABAB } \\
\text { ABAB CDC } \\
\text { DCD }\end{array}$ & Consonante & $\begin{array}{l}\text { Soneto } \\
\text { alejandri- } \\
\text { no }\end{array}$ \\
\hline Sola tú & 20 & Regular & $\begin{array}{l}\text { Endecasílabos y } \\
\text { heptasílabos }\end{array}$ & $-A$ & Asonante & $\begin{array}{l}\text { Silva arro- } \\
\text { manzada }\end{array}$ \\
\hline $\begin{array}{l}\text { Lejana como } \\
\text { Dios }\end{array}$ & 16 & Regular & $\begin{array}{l}\text { Endecasílabos y } \\
\text { heptasílabos }\end{array}$ & $-\mathrm{A}$ & Asonante & $\begin{array}{l}\text { Silva arro- } \\
\text { manzada }\end{array}$ \\
\hline $\begin{array}{l}\text { Camino del } \\
\text { Guadarrama }\end{array}$ & 36 & Regular & Octosílabos & $-\mathrm{a}$ & Asonante & Romance \\
\hline El viejo estío & 14 & Regular & Endecasílabos & $\begin{array}{l}\text { ABBA ABBA } \\
\text { CDE CDE }\end{array}$ & Consonante & Soneto \\
\hline $\begin{array}{l}\text { Roto mi } \\
\text { corazón }\end{array}$ & 14 & Regular & Endecasílabos & $\begin{array}{l}\text { ABBA ABBA } \\
\text { CDE CDE }\end{array}$ & Consonante & Soneto \\
\hline $\begin{array}{l}\text { Joaquina } \\
\text { Márquez }\end{array}$ & 140 & Regular & Octosílabos & $-a$ & Asonante & Romance \\
\hline De lejos & 52 & Regular & Octosílabos & $-\mathrm{a}$ & Asonante & Romance \\
\hline $\begin{array}{l}\text { A un pino del } \\
\text { Guadarrama }\end{array}$ & 174 & Regular & Heptasílabos & $-\mathrm{a}$ & Asonante & $\begin{array}{l}\text { Romance } \\
\text { heptasilá- } \\
\text { bico }\end{array}$ \\
\hline
\end{tabular}


Quizás el dato que llama más la atención es el paso a una métrica completamente regular, acompañada siempre de rima. Son 18 composiciones de las cuales 8 riman en asonante y 10 en consonante. Predominan los versos de ritmo endecasilábico, y de ello da cuenta la gran cantidad de sonetos, 6 , y silvas, 4 . De hecho, en metro de sílabas pares, que no sigue, por tanto, el ritmo yámbico, solo encontramos tres romances octosilábicos.

En todo caso, dentro de esta regularidad a la que hemos aludido vemos también una tendencia a la variedad, tanto versal como estrófica: coplas heptasilábicas, dos sonetos en alejandrinos, silvas arromanzadas y romances.

Encontramos también, por tanto, una pequeña parcela de experimentación formal, ligada, en esta ocasión, a la limitación de una métrica estricta, a la contención. Ya en el apartado anterior habíamos hablado de la encrucijada de influencias que en esta época actúa sobre la poesía de Panero. En estos Versos al Guadarrama son más visibles algunas que en los anteriores poemas se dejaban, apenas, vislumbrar. El influjo de Antonio Machado es decisivo para esta obra (pensemos en poemas como «Sola tú»), como también el de Lorca (el romance «Joaquina Márquez»). Sin embargo, apunta Huerta Calvo que la más decisiva de estas influencias es la de Jorge Guillén, «de quien aprendió Panero la técnica de disciplinar el verso mediante un léxico preciso, casi matemático, huérfano de adjetivos, y encauzado en una sintaxis mesurada y austera ${ }^{33}{ }^{»}$. Como venimos diciendo, si en Primeros poemas influyen escritores más ligados al creacionismo y al surrealismo como Huidobro, Gerardo Diego, o Aleixandre, en Versos al Guadarrama se hace mucho más visible la influencia de Lorca, Jorge Guillén y de una de sus principales influencias posteriores: Antonio Machado.

El soneto es la forma poética más utilizada en este poemario. Llama la atención el hecho de que se utiliza siempre un mismo esquema rimático en los sonetos en endecasílabos (ABBA ABBA CDE CDE) y siempre el mismo, pero distinto al anterior, en los sonetos en alejandrinos (ABAB ABAB CDC DCD). Ambos esquemas responden a una distribución canónica de la rima

$\overline{{ }^{33} I b i d ., ~ p p . ~ 35-36 . ~}$ 
en el soneto, sin embargo, el autor decide reservar uno de ellos para cada metro. El tipo de soneto que hace Panero en Versos al Guadarrama no tiende a lo barroco, sino hacia una concentración del lenguaje, que da sensación de naturalidad expresiva. Dice Huerta Calvo: "Ya en los años 30, mientras se daba a la elocuencia tardovanguardista, el poeta se ejercitaba en privado con la severidad casi monacal del verso guilleniano ${ }^{34} \gg$. Este arte es deudor, para el crítico, de Guillén y de Azorín, y mediante esa sobriedad y concisión en la expresión logra «introducir frescura en las estructuras métricas tanto de arte mayor como de arte menor ${ }^{35} \gg$.

\section{Conclusiones}

Después de este análisis de la métrica utilizada en esta primera etapa por Leopoldo Panero podemos concluir que la parte formal del poema no constituye únicamente un molde necesario para la expresión, sino que tiene valor propio, ya que está sumamente cuidada y pensada. Se utilizan una gran variedad de formas, si bien se privilegia la métrica regular para un tipo de poesía más tradicional, y el verso libre aparece más ligado a las composiciones de vanguardia en este primer momento. Sin embargo, aunque Versos al Guadarrama está escrito íntegramente en verso regular, el versolibrismo se retomará posteriormente en la obra de Panero, por lo que estos inicios pueden ser vistos como una etapa fértil de prueba.

Es interesante estudiar esta primera etapa de búsqueda, en un poeta que posteriormente Siebenmann describe de la siguiente manera: «La abdicación de toda acrobacia formal, de cualquier agudeza conceptual y del tentador desenfreno imaginativo ${ }^{36} \gg$.

Vemos entonces en esta etapa dos tipos de versificación, dos tipos de hacer poesía, en dos poemarios aparentemente opuestos. Uno que permite la verbosidad, la amplitud del verso, las imágenes sorprendentes, y que va ligado al versolibrismo. Otro más comedido, más replegado sobre sí mismo, más emocional,

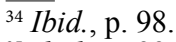

${ }^{35}$ Ibid., p. 99.

${ }^{36}$ Siebenmann, Gustav: Los estilos poéticos en España desde 1900. Madrid: Gredos, 1973, p. 95. 
y, si se quiere, más humano, para el que se utiliza la métrica regular. Sin embargo, con el lógico cambio y avance en su expresión y motivos, finalmente el poeta astorgano conseguirá en su obra posterior conjugar una expresión sincera, que busca menos el juego de ingenio y más la conmoción del alma, con varios tipos de versificación, aportándole cada uno de ellos algo distinto. Huerta Calvo establece una clara distinción entre el verso libre de estas primeras composiciones y el de su obra posterior: «El versolibrismo no es, en sí mismo, garante de una naturalidad expresiva. Bien pueden acreditarlo sus inmaduros poemas de anteguerra», aunque reconoce el gran valor de sus poemas versolibristas posteriores, que suponen «un nuevo reto para el poeta en su búsqueda cada vez más evidente de la palabra justa ${ }^{37} \gg$.

Así, el examen de esta primera producción, que en ocasiones podemos casi considerarla como ensayo o ejercitación poética, es rico en consecuencias, ya que revela la atención que el poeta astorgano presta desde un primer momento a las formas métricas, la indagación y búsqueda de su propia voz, y la adecuación de los moldes métricos según el tipo de expresión buscado.

\section{Bibliografía utilizada}

ALONSO, Dámaso: «La poesía arraigada de Leopoldo Panero», en PANERO, Leopoldo: Obra completa, edición crítica de Javier Huerta Calvo con la colaboración de Javier Cuesta Guadaño y Juan José Alonso Perandones. Astorga: Ayuntamiento de Astorga, 2007, pp. XXV-L (Publicado por primera vez en 1949 en Cuadernos Hispanoamericanos, 9, pp. 691-709). BOUSOÑNO, Carlos: La poesía de Vicente Aleixandre. Madrid: Gredos, 1977. GULLÓN, Ricardo: La juventud de Leopoldo Panero. León: Diputación de León, 1985.

HUERTA CALVO, Javier: «Aparato crítico a Obra Completa» en PANERO, Leopoldo: Obra completa, vol. II, edición crítica de Javier Huerta Calvo con la colaboración de Javier Cuesta Guadaño y Juan José Alonso Perandones. Astorga: Ayuntamiento de Astorga, 2007.

— «Introducción a En lo oscuro», en PANERO Leopoldo: En lo oscuro, edición crítica de Javier Huerta Calvo con la colaboración de Javier Cuesta Guadaño y Juan José Alonso Perandones. Astorga: Ayuntamiento de Astorga, 2011.

${ }^{37}$ Huerta Calvo, Javier: «Introducción a En lo oscuro», cit., p. 99. 
MÁRQUEZ, Miguel Ángel: «El versículo en el verso libre de ritmo endecasilábico». Bulletin of Hispanic studies, 2000, 77, 3, pp. 217-234.

- «Juan Ramón Jiménez: Etapa americana». Rhythmica. Revista española de métrica comparada. 2003, I, pp. 149-181.

PANERO, Leopoldo: Obras completas Vol. I, Poesías, edición prologada, ordenada y anotada por Juan Luis Panero. Madrid: Editorial Nacional, vol.1. Poesía I - vol.2. Poesía II - vol.3. Prosa, 1973.

- Obra completa, edición crítica de Javier Huerta Calvo con la colaboración de Javier Cuesta Guadaño y Juan José Alonso Perandones. Astorga: Ayuntamiento de Astorga, 2007.

- «Poesía de ayer», en PANERO, Leopoldo: Obra completa [Prosa], edición crítica de Javier Huerta Calvo con la colaboración de Javier Cuesta Guadaño y Juan José Alonso Perandones. Astorga: Ayuntamiento de Astorga, 2007.

- En lo oscuro, edición de Javier Huerta Calvo. Madrid: Cátedra, 2011.

- «Unas palabras sobre mi poesía», en PANERO, Leopoldo: En lo oscuro, edición crítica de Javier Huerta Calvo con la colaboración de Javier Cuesta Guadaño y Juan José Alonso Perandones. Astorga: Ayuntamiento de Astorga, 2011.

PARAÍSO, Isabel: El verso libre hispánico: orígenes y corrientes. Madrid: Gredos, 1985.

ROSALES, Luis: «Leopoldo Panero hacia un nuevo humanismo». Cuadernos Hispanoamericanos, 1965, 187-188, pp. 35-79.

SERRANO, Atanasio: «Leopoldo Panero, el hombre y el poeta: (en el centenario del nacimiento de L. Panero, 1909-2009)». Tierras de León: Revista de la Diputación Provincial, 2007, 45, 124-125, pp. 33-48.

SIEBENMANN, Gustav: Los estilos poéticos en España desde 1900. Madrid: Gredos, 1973.

UTRERA TORREMOCHA, María Victoria: Historia y teoría del verso libre. Sevilla: Padilla Libros, 2001. 